\title{
APLIKASI PELAYANAN PENGADUAN MAINTENANCE DIVISI TEKNIK BERBASIS ANDROID PADA PERGURUAN TINGGI RAHARJA
}

\author{
Aris $^{1}$, Maryanih ${ }^{2}$, Syinthia Ricka Arrianti ${ }^{3}$ \\ Dosen Manajemen Informatika STMIK RAHARJA ${ }^{1}$, Mahasiswa Sistem Informasi STMIK \\ RAHARJA ${ }^{2,3}$ \\ E-mail: aris@raharja.info ${ }^{1}$,maryanih@raharja.info ${ }^{2}$,syinthia@raharja.info ${ }^{3}$
}

\begin{abstract}
ABSTRAK
Pengembangan Sistem Pelayanan untuk bagian Teknik berupa Sistem Aplikasi Maintenance Request, yang digunakan untuk meningkatkan pelayanan hanya kepada manajemen yaitu staf. Kepuasan pelanggan merupakan evaluasi spesifik terhadap keseluruhan pelayanan yang diberikan oleh bagian teknik, sehingga kepuasan pengguna jasa di divisi teknik hanya dapat dinilai berdasarkan pengalaman yang pernah dialami saat proses pemberian pelayanan. Kepuasan pelanggan terutama dibidang jasa maintenance menjadi keharusan agar pelayanan di kembangkan lebih luas untuk Dosen dan mahasiswa. Dengan adanya pengembangan sistem aplikasi maintenance request dari website di rubah menjadi mobile, yaitu berbasis Android yang dapat memudahkan user dapat melakukan keluhan dengan smartphone berbasis android, sehingga sangat membantu bagian teknik untuk menampung semua keluhan user. Aplikasi Maintenance Request berbasis Android ini dapat melaporakan secara cepat setiap request maintenance yang masuk dari user ke petugas teknik, sehingga mendapat respon yang lebih efektif dan secara efesien dalam mengukur tingkat waktu penyeleseain dalam maintenance.
\end{abstract}

Kata kunci: Aplikasi, Mobile ,Android, Maintenance request

\begin{abstract}
Development of Service System for engineering section in the form of Application Maintenance Request System, which is used to improve services only to management, namely staf. Customer satisfaction is a specific evaluation of the overall services provided by the engineering department. so that the satisfaction of service users in the engineering division can only be judged based on the experience that has been experienced during the service delivery process. Customer satisfaction, especially in the area of maintenance services, is a must so that the service is developed more broadly for lecturers and students. With the development of an application system maintenance requests from websites are changed to mobile, that is based on Android which can make it easier for users to make complaints with Android-based smartphones, so it is very helpful for the engineering section to accommodate all user complaints. This Android-based Maintenance Request application can report quickly any maintenance requests that come from the user to the engineering officer, so that it gets a more effective and efficient response in measuring the level of time during maintenance.
\end{abstract}

Keywords: Application, Mobile, Android, Maintenance request

\section{PENDAHULUAN}

Diharapkan Perguruan Tinggi Raharja mampu memenuhi tuntutan untuk peningkatan pengembangan dan pelayanan pendidikan.Oleh sebab itu penting bagi Perguruan Tinggi Raharja untuk memanfaatkan seluruh sumber daya yang dimilikinya secara optimal dengan tujuan untuk pencapaian performansi yang tinggi. 
Masalah yang muncul sejauh ini terhadap Perguruan Tinggi Raharja adalah kondisi dimana bagian teknik melayani Manajemen dan mahasiswa yang terus bertambah khususnya mahasiswa, sehingga menyebabkan tingkat pelayanan yang ada selama ini masih belum memuaskan dengan standard baku pelayanan teknik yang belum terlaksana dengan baik, Akan tetapi dengan strategi ini pihak Kampus terus berusaha agar biaya yang dikeluarkan oleh Perguruan Tinggi Raharja dalam membayar biaya oprasional terhadap maintenance teknik dapat optimal sesuai dengan kebutuhan manajemen dan mahasiswa .Dari masalah tersebut peneliti melihat adanya suatu peluang permasalahan yang dapat dijadikan bahan untuk diteliti. Dimana berdasarkan bagian Teknik Pada Perguruan Tinggi Raharja yang cukup luas dan banyak dalam segi pelayanan, peneliti akan mencoba membantu untuk melakukan suatu upaya perbaikan kualitas unit pelayanan teknik agar tujuan kampus dapat tercapai.

\section{Metode Penelitian}

\subsection{Diagram Alur Penelitian}

Mengenai metodelogi yang digunakan oleh penulis dalam melakukan peneletian ini. Metodelogi merupakan gambaran dan urutan pengerjaan yang digunakan dalam penelitian, diharapkan akan mendeskripsikan sistem pengembang pelayanan teknik.

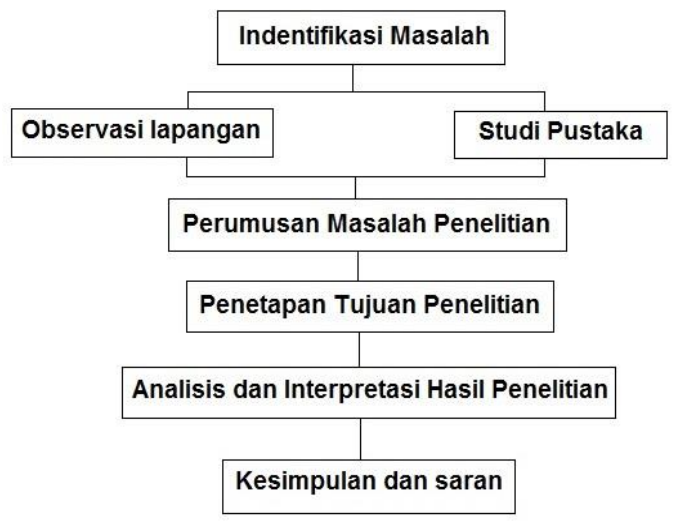

Gambar .1 Diagram Alir Metodologi Penelitian

Identifikasi masalah dilakukan untuk mengetahui gambaran permasalahan yang terjadi di tempat penelitian yang selanjutnya menjadi dasar dilakukannya penelitian ini. Proses identifikasi dilakukan dengan cara pengamatan dan wawancara dengan para pengguna jasa terutama mahasiswa dan staf manajemen Perguiruan Tinggi Raharja. Dari hasil identifikasi masalah, hipotesis awal yang didapat adalah terdapat kesenjangan antara harapan dan penilaian atas kualitas pelayanan jasa bagian Teknik .

\subsection{Perumusan Masalah Penelitian}

Setelah dilakukan identifikasi permasalahan, maka permasalahan yang dapat dirumuskan dalam penelitian ini adalah bagaimana menganalisis sistem pelayanan jasa maintenance yang ada di Bagian Teknik Perguruan Tinggi Raharja.

\subsection{Analisis dan Interpretasi Hasil Penelitian}

Dari pengujian pelayanan teknik yang ada ternyata masih banyak permintaan yang masih tertunda dan tidak di kerjakan oleh bagian teknik, oleh karna sistem pelaporan user ke bagian teknik tidak mencangkup ke seluruhan ke staf teknik, menyebabkan permintaan pelayanan untuk maintenance tidak terselesaikan dengan baik dan tetap waktu. Untuk itu perlu pengembangan sistem Aplikasi yang dapat menampung semua keluhan user agar dapat terkontrol oleh bagian teknik dalam 
mengelolah Request yang masuk, yang dapat meningkatkan pelayanan bagian Teknik yang dirasakan oleh pengguna terhadap pelayanan yang diberikan oleh Perguruan Tinggi Raharja.

\subsection{Pengacuan Pustaka}

Ana Nur Cahyanti dkk.(2012) Penelitiannya menghasilkan aplikasi pelayanan perangkat lunak yang diharapkan dapat membantu Puskesmas Pakis Baru dalam memproses pengolahan data register pasien yang dapat mempermudah pencarian dan pembuatan laporan.[1]

Penelitian sejenis juga dikembangkan Yonathan Liliek Prihartanto (2013)Dengan adanya Sistem Informasi Manajemen Agenda, diharapkan menghasilkan aplikasi pelayanan yang dapat mengelola surat masuk dan keluar sesuai alur yang di tetapkan, dan dapat menyelesaikan masalah yang ada saat ini. Penelitian ini dilakukan untuk membuat aplikasi berbasis web, yang dapat mengelola surat masuk dan keluar secara efektif sesuai alur yang telah ditetapkan oleh Badan Pelayanan Perizinan Terpadu (BPPT) Kabupaten Karanganyar.[2]

Penciptaan layanan informasi akademik berbasis Short Message Service oleh M Affan Effendi.dkk(2012) digunakan untuk memperoleh informasi akademik melalui query terhadap database yang telah tersedia, informasi-informasi yang dapat diakses adalah informasi mengenai Jadwal Kulliah, Jadwal Ujian, Pengumuman, dan Nilai. Bahasa yang digunakan untuk mengimplementasikan layanan informasi akademik berbasis Short Message Service adalah bahasa Visual Basic 6.0 .[3]

M.A. Muslim .(2012) juga membuat Sistem Informasi Jurusan Berbasis Web ada Jurusan Matematika Universitas Negeri Semarang merupakan suatu sistem yang memberikan informasi kepada dosen, karyawan, mahasiswa, alumni serta masyarakat luas secara online, sehingga membantu kecepatan dan kualitas pelayanan dalam penyampaian informasi. Selain itu dengan berbasiskan web maka informasi data dapat diakses dengan waktu dan tempat yang tidak ditentukan. Pada sistem ini, pengguna mempunyai hak akses untuk masing masing tingkatan user, dalam mendapatkan informasi .[4]

Ovi Dyantina.dkk (2014) juga melakukan penelitian mengenai pelayanan menggunakan CRM adalah strategi pemasaran untuk menciptakan dan menjaga hubungan baik dengan pelanggan dan mengurangi kemungkinan pelanggan beralih ke pesaing lainnya. penelitiannya menyajikan analisis pengembangan CRM berbasis web di Sistem Informasi Pemasaran di Toko YEN-YEN.[5]

\section{HASIL DAN PEMBahaSAN}

3.1 Use case diagram Aplikasi Sistem Maintenance request

Pembahasan terhadap hasil penelitian dan pengujian yang diperoleh disajikan dalam bentuk prosedur sistem yang dibuat untuk menspesifikasikan, mengakuratkan pemahaman sistem yang diusulkan, akan digambarkan kedalam bahasa visual untuk pemodelan dan komunikasi sistem dengan use case diagram sebagai berikut : 


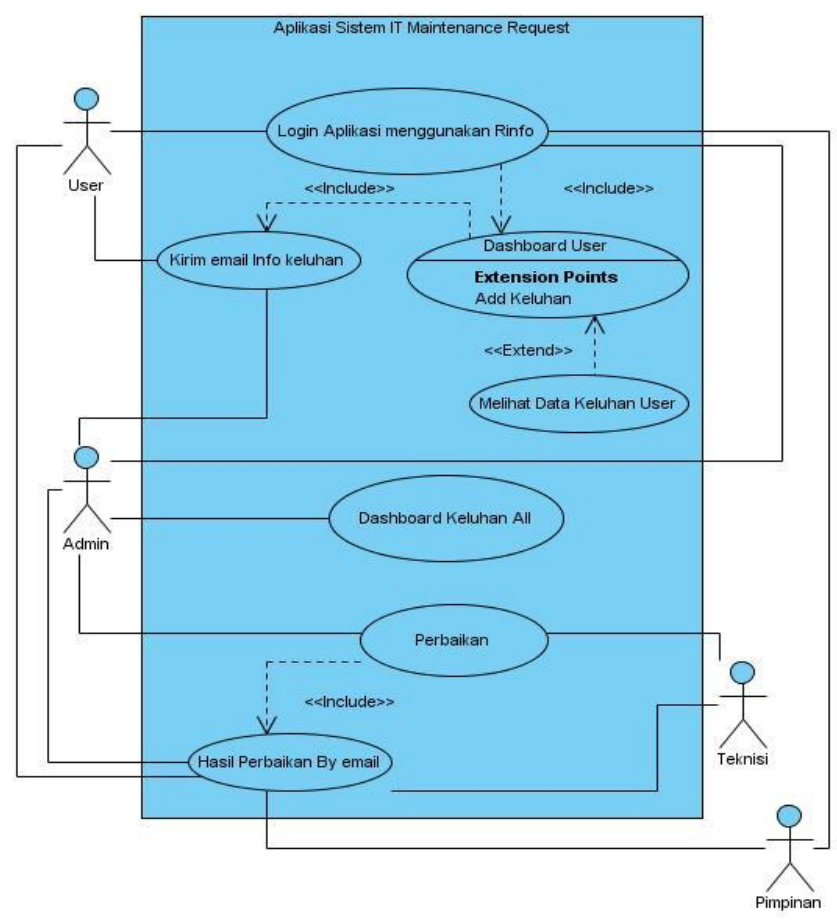

Gambar 2. Use Case Diagram Sistem Usulan Request Perbaikan

Pada gambar 2 . adalah alur skenario use case sistem berjalan request perbaikan staff dijelaskan bahwa terdapat :

a. 1 (satu) sistem yang mencakup seluruh kegiatan Sistem request perbaikan pada Perguruan Tinggi Raharja.

b. 4 (empat) Actor yang melakukan interaksi dengan Sistem request perbaikan pada Perguruan Tinggi Raharja yang diusulkan, yaitu: Staff pengaju maintenance/perbaikan, admin teknik, staff teknik, dan Pimpinan Teknik.

c. 6 (enam) Use Case yang mendeskripsikan kegiatan yang dilakukan oleh aktor tersebut yang melibatkan Sistem Request Maintenance dan perbaikan staff yang berjalan saat ini, yaitu: login dengan email Rinfo, Dasboard Maintenance user, Mengisi add keluhan Request Maintenance, menerima info keluhan melalui emai, hasil perbaikan di kirim kembali ke email pimpinan, user dan staf teknik. 
3.2 Tampilan Hasil Penelitian

3.2.1 Menu Login

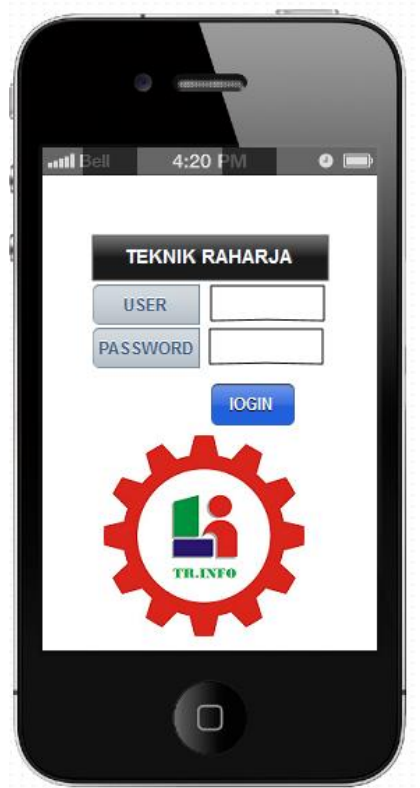

Gambar 3. Menu Login

Pada gambar 3. merupakan tampilan login untuk masuk ke teknik.raharja.info untuk Add keluhan maintenance. Memulai masuk ke sistem teknik.raharja.info.

\subsubsection{Menu Dashboard User}
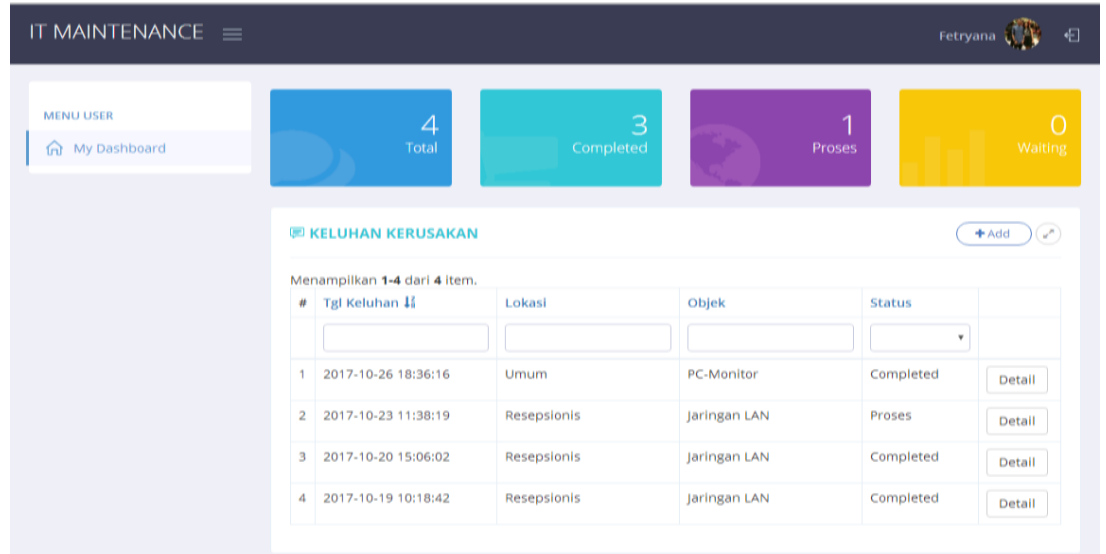

Gambar 4. Menu Dashboard user

Pada gambar 4. adalah area Dashboard user dapat menampilkan semua request maintenance yang dilakukan oleh user 
3.2.3 Tampilan Add request maintenance

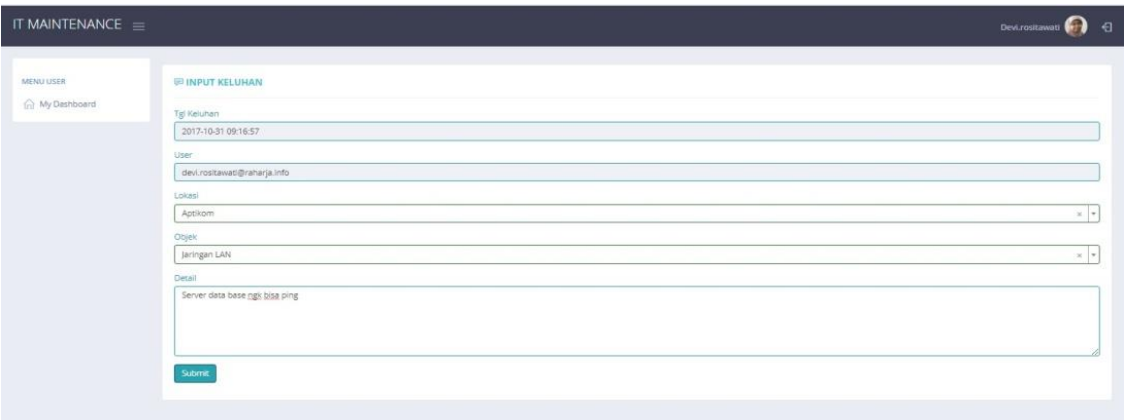

Gambar 5. Tampilan Add request maintenance

Pada gambar 5. adalah menu ini menampilkan isian Add Request maintenance yang di isi oleh user terhadap keluhan yang terjadi pada perangkat komputer kerjanya, yang di kirim ke Sistem untuk bagian teknik dan akan di tindak lanjuti oleh petugas Teknik.

3.2.4 Informasi Add keluhan Maintenance yang langsung direspon oleh email

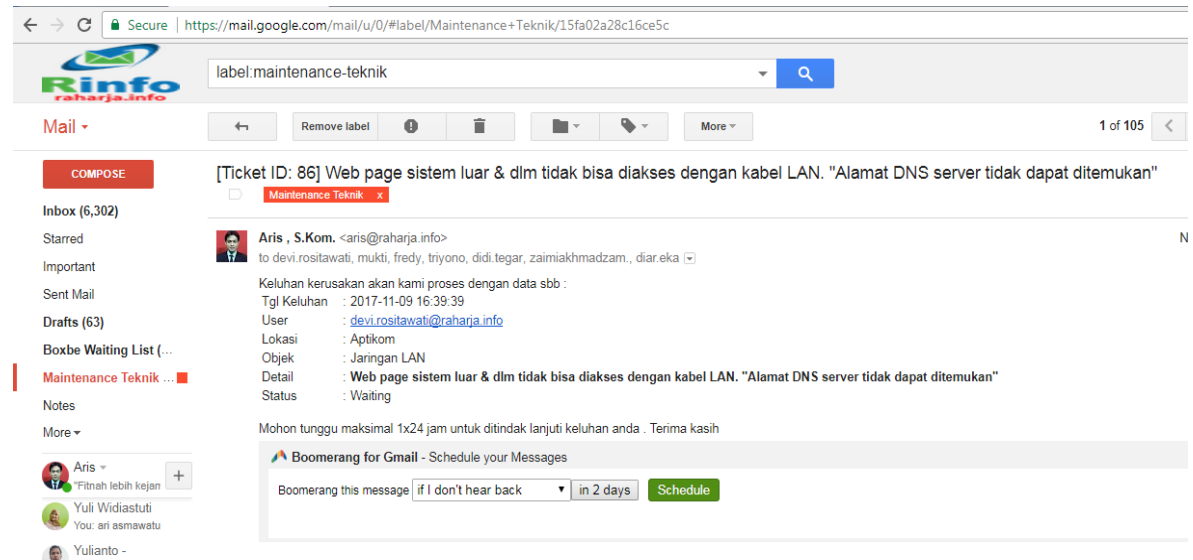

Gambar 6. Tampilan Dasboard Garfik Maintenance

Pada Gambar 6 dapat dilihat hasil Add keluhan User yang melakukan di dalam Aplikasi Sistem maintenanace langsung di balas oleh email secara otomatis untuk menginformasikan keluhannya.Dan informasi ini juga terkirim ke petugas Teknik serta Pimpinan.

3.2.5 Hasil tindakan Maintenance berupa Informasi di Dashboard User

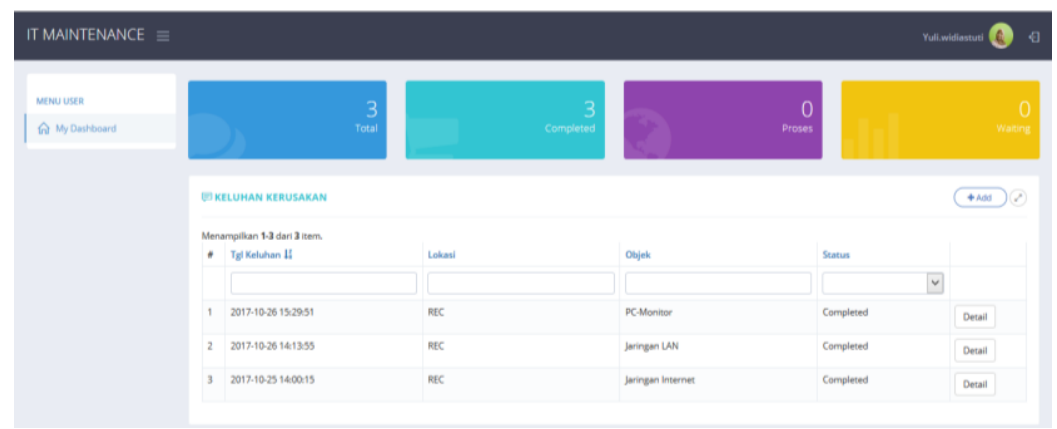

Gambar 7. Tampilan Dasboard Hasil Maintenance 
Pada Gambar 7 dapat dilihat hasil maintenance yang sudah di lakukan oleh petugas teknik dengan status complied.sehingga user dapat mengetahui hasil dari Request Maintenance yang sudah di kerjakan bagian teknik.

3.2.6 Hasil Dashboard Maintenance

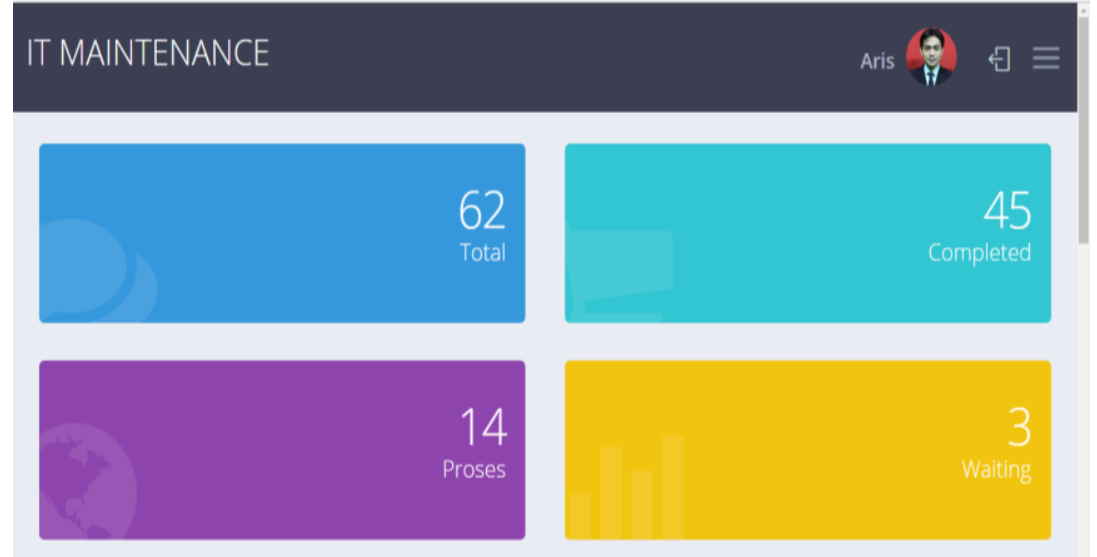

Gambar 8. Tampilan Dasboard Garfik Maintenace

Pada gambar 8. Menampilkan Dashboard Maintenance bisa di tampilkan secara keseluruhan total request maintenance yang masuk ke sistem aplikasi maintenance request dan ada tampilan hasil tindakan yaitu jumlah completed pekerjaan, jumlah Proses pekerjaan, dan jumlah waiting pekerjaan.ini bisa menjadi pengambilan keputusan oleh pimpinan.

\subsubsection{Hasil Grafik Dashboard Maintenance}

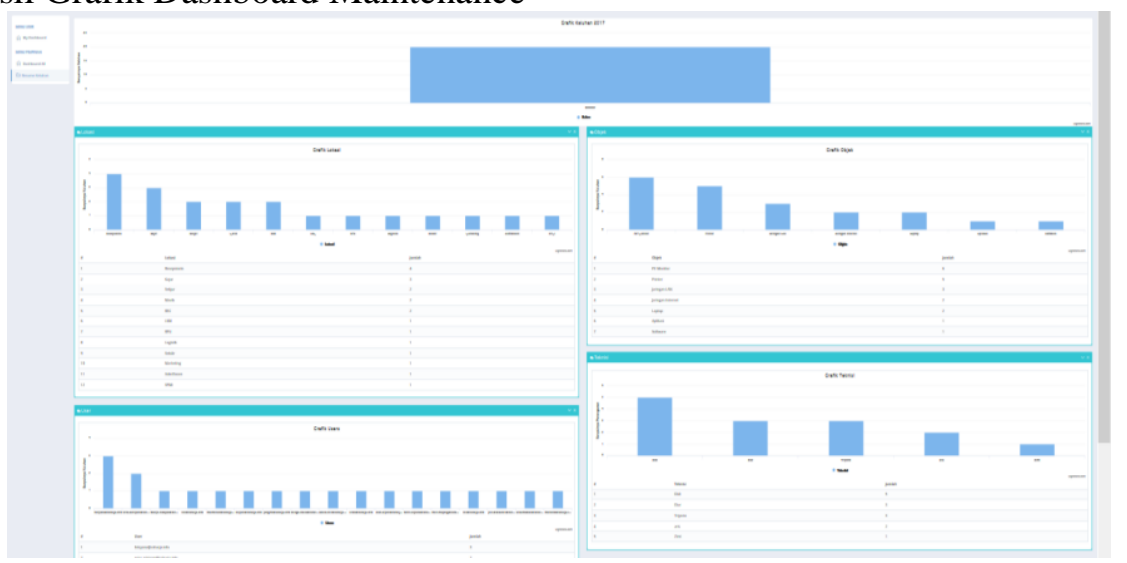

Gambar 9. Tampilan Garfik Dasboard Maintenace

Pada gambar 9. Adalah Grafik Dashboard Maintenance dapat di lihat secara grafik tingkat hasil penyelesaian Request maintenance yang di lakukan oleh bagian teknik secara global, baik dari user, Divisi, Objek kerusakan,dan petugas teknik.

\section{KESIMPULAN}

Kesimpulan didapatkan dari rumusan masalah yang telah dibuat sebelumnya. Berdasarkan rumusan masalah yang ada, didapat kesimpulan yaitu: 
1. Pada penelitian ini telah dibangun sistem pelayanan pada bagian Teknik dengan menggunakan Aplikasi Maintenance Request Sistem Berbasis Android sehingga setiap user/staf manajemen Raharja dapat menyampaikan keluhan dalam permasalahan penggunaan perangkat komputer.Sehingga permintaan maintenance dapat disampaikan ke petugas teknik dengan respond yang cepat ditangani.

2. Jaminan yang di berikan oleh bagian Teknik merupakan pelayanan yang sudah sangat di harapkan jika user melakukan request ke sistem Aplikasi Maintenance Request Berbasis Android.Jika user login dan mengisi keluhan maka secara otomatis system akan memberi balasan melalui email yang langsung di tunjukan ke semua staf Teknik, yang akan langsung di tindak lanjuti secara cepat .

3. Dalam Proses maintenance bagian Teknik sudah secara otomatis dapat meningkatkan efesiensi waktu yang di kerjakan, dimana data keluhan yang masuk dapat dilihat dan di kerjakan secara efesien.Sehingga User tidak menunggu terlalu lama dalam penanganan.

\section{SARAN}

Berdasarkan hasil penelitian, selanjutnya peneliti dapat memberikan beberapa saran berupa masukan yang ditujukan kepada obyek penelitian dan untuk penelitian selanjutnya.

1. Dalam proses implementasi sistem pelayanan di bagian teknik dengan menggunakan Aplikasi Maintenance Request Sistem Berbasis Android ini sudah dilakukan dengan penempatan secara online, dan untuk kedepan dapat dilakukan pengembangan isi dari konten.

2. Perlu adanya pengembangan pada Aplikasi Maintenance Request Sistem Berbasis Android sehingga penggunaan data kerusakan perangkat baik hardware maupun software dapat dilihat lama waktu pengerjaan maintenance.

3. Penggunaan Dashboard Informasi Maintenance dapat digunakan oleh tingkat pimpinan yaitu di Middle manajemen di pimpinan bagian operasi yaitu Asisten direktur Operasi, untuk mengambil keputusan dari tingkat maintenance yang telah di kerjakan oleh bagian teknik.

\section{DAFTAR PUStaka}

[1] Ana Nur Cahyanti dkk.2012, Pembangunan Sistem Informasi Manajemen Puskesmas Pakis Baru Nawangan., vol 4.edisi 4.Journal Speed.Boyolali

[2] Yonathan Liliek Prihartanto .2013 Sistem Informasi Manajemen Agenda Pada Badan Pelayanan Perijinan Terpadu Kabupaten Karanganyar .vol 3.edisi 3.journal Speed .Boyolali

[3] M Affan Effendi.dkk(2012).Perancangan Sistem Layanan Informasi Akademik Berbasis Short Message Service.vol 3.No 4. Journal Speed.Boyolali

[4] M.A. Muslim(2012). Pengembangan Sistem Informasi Jurusan Berbasis web untuk meningkatkan Pelayanan dan Akses Informasi.vol 35.No.1.,Jurnal MIPA.Semarang

[5] Ovi Dyantina.dkk (2014). Penerapan Customer Relationship Management (CRM) Berbasis Web (Studi Kasus Pada Sistem Informasi Pemasaran di Toko YEN-YEN).vol 4 .No 2 .Journal Of Information Systems. Palembang. 